$\underline{\text { Supporting Information }}$

\title{
Alkaline Battery Separators with High Electrolyte Absorption from Forced Assembly Co-extruded Composite Tapes
}

\author{
Xinting Wang, Jialu Lin, Vidya Viswanath, Andrew Olah, Eric Baer* \\ Center for Layered Polymeric Systems (CLiPS) \\ Department of Macromolecular Science and Engineering \\ Case Western Reserve University, Cleveland, OH 44106-7202, USA
}

* Corresponding author. 2100 Adelbert Rd., Kent Hale Smith 422, Cleveland, OH 44106, USA.

Tel: +1 216368 4203. E-mail address:: exb6@case.edu (E. Baer) 
$\underline{\text { Experimental Details }}$

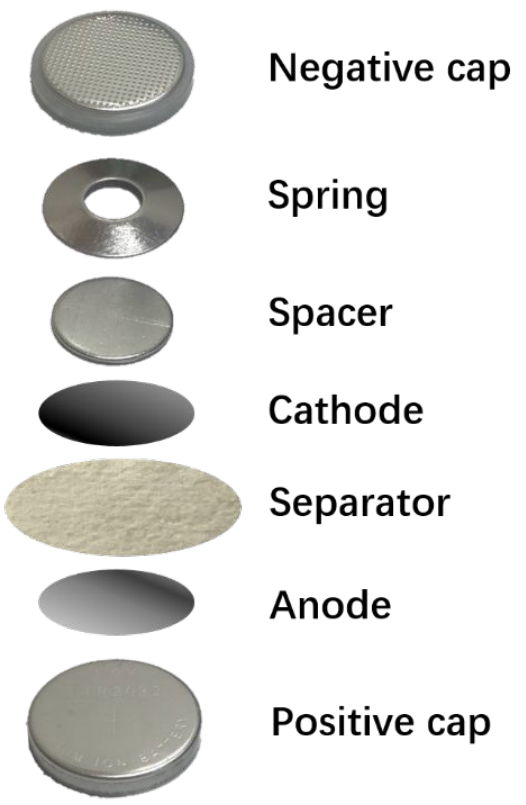

Figure S1. Coin cell configuration 


\section{$\underline{\text { Results }}$}

Table S1. Mechanical properties of untreated separators delaminated at different conditions.

\begin{tabular}{ccc}
\hline Delamination conditions & $\begin{array}{c}\text { Modulus } \\
{[\mathbf{M P a}]}\end{array}$ & $\begin{array}{c}\text { Tensile stress at } \\
\text { maximum load } \\
\text { [MPa] }\end{array}$ \\
\hline Speed: $(150 \mathrm{rpm}$, 150rpm) & $157 \pm 29$ & $7.9 \pm 1.5$ \\
$1000 \mathrm{psi}$ & & \\
Speed: $(150 \mathrm{rpm}, 150 \mathrm{rpm})$ & $248 \pm 29$ & $14 \pm 0.5$ \\
$1000 \mathrm{psi}$ & & \\
Speed: $(100 \mathrm{rpm}, 100 \mathrm{rpm})$ & $135 \pm 6.7$ & \\
\hline
\end{tabular}


Table S2. The effect of treatment time on KOH uptake and contact angle of (a) PP/HDPE separator, (b) PP/PA6 separator. The error bar is based on measurements of 10 specimens.

\begin{tabular}{|c|c|c|}
\hline Time(s) & $\begin{array}{c}\text { KOH } \\
\text { uptake(\%) }\end{array}$ & $\begin{array}{c}\text { KOH } \\
\text { Contact } \\
\text { Angle }\end{array}$ \\
\hline 0 & $461 \pm 53$ & $126^{\circ} \pm 1$ \\
\hline 5 & $429 \pm 46$ & $123^{\circ} \pm 2$ \\
\hline 15 & $532 \pm 62$ & $110^{\text {o } \pm 1}$ \\
\hline 20 & $661 \pm 55$ & $103^{\circ} \pm 1$ \\
\hline 25 & $1046 \pm 54$ & $0^{\mathbf{o}}$ \\
\hline 30 & $1140 \pm 65$ & $0^{\mathbf{o}}$ \\
\hline 45 & $1191 \pm 43$ & $0^{\mathbf{o}}$ \\
\hline 60 & $1325 \pm 49$ & $0^{\mathbf{o}}$ \\
\hline 90 & $1351 \pm 63$ & $0^{\mathbf{o}}$ \\
\hline 120 & $1355 \pm 57$ & $0^{\mathbf{o}}$ \\
\hline
\end{tabular}

(a)

\begin{tabular}{|c|c|c|}
\hline Time(s) & $\begin{array}{c}\text { KOH } \\
\text { uptake(\%) }\end{array}$ & $\begin{array}{c}\text { KOH Contact } \\
\text { Angle }\end{array}$ \\
\hline 0 & N/A & $132^{\mathbf{o}} \pm 1$ \\
\hline 5 & $716 \pm 24$ & $105^{\circ} \pm 2$ \\
\hline 15 & $989 \pm 56$ & $0^{\mathbf{o}}$ after $60 \mathrm{~s}$ \\
\hline 20 & $1463 \pm 71$ & $0^{\mathbf{o}}$ after $30 \mathrm{~s}$ \\
\hline 25 & $1453 \pm 63$ & $0^{\mathbf{o}}$ \\
\hline 30 & $1487 \pm 58$ & $0^{\mathbf{o}}$ \\
\hline 45 & $1489 \pm 39$ & $0^{\mathbf{o}}$ \\
\hline 60 & $1588 \pm 62$ & $0^{\mathbf{o}}$ \\
\hline 90 & $1560 \pm 49$ & $0^{\mathbf{o}}$ \\
\hline 120 & $1585 \pm 54$ & $0^{\mathbf{o}}$ \\
\hline
\end{tabular}

(b) 